\title{
Estimating post- and pre-mitigation contingency in construction
}

\author{
A. Salah \& O. Moselhi \\ Department of Building, Civil and Environmental Engineering, \\ Concordia University, Canada
}

\begin{abstract}
Contingency is necessary to mitigate and control risk associated with construction projects. Successful contingency estimation and risk mitigation strategies can help project managers to effectively control cost and schedule. Some practitioners mitigate risk by transferring it to another party with less effort and minimum cost. However, this may lead to undesirable results such as; useless depletion of contingency, cost overrun, and project delay. This paper differentiates between two types of project contingency; pre-mitigation, and post-mitigation. It also proposes a new estimation method for pre-mitigation and post mitigation contingencies using fuzzy set theory. The proposed pre-mitigation contingency estimation makes use of qualitative and quantitative assessment of risks associated with projects. Post mitigation contingency (POSTMC) estimation makes use of newly introduced planned efficiency factor $(\mathrm{PEF})$. That factor is calculated using mitigation strategy cost, pre-mitigation contingency (PREMC) and several sub-factors such as; mitigation efficiency on probability (MEFP), mitigation efficiency on consequences (MEFC), and mitigation efficiency (MEF). This paper provides a decision support tool; expected to help project managers in estimating and evaluating pre-mitigation and post mitigation contingencies using a set of strategies during project life cycle. The evaluation of post mitigation efficiency allows user to update the risk mitigation plan (i.e. risk response plan) for future projects. In addition to that, it allows users to maximize profit and minimize cost without compromising the efficiency of the selected risk mitigation strategies. Numerical example is presented to illustrate the application and capabilities of proposed method in estimation the pre-mitigation and post mitigation contingency. It also
\end{abstract}


demonstrates the capacity of the proposed method in selecting most effective mitigation strategies for risks associated with the project.

Keywords: risk analysis, contingency, estimating, pre-mitigation, postmitigation, construction.

\section{Introduction}

Construction industry expands continuously, which leads to considerable changes in construction project in terms of volume and complexity. Such increase incorporates significant level of uncertainty, in terms of cost and schedule, which requires additional efforts to assess and manage. Mitigation strategies are commonly used to manage a risk and alleviate its consequences. However, estimating risk mitigation cost, called also contingency, represents a challenge for parties involved in the project. Thus, risk management practitioners tend to transfer risk items to others with minimum effort and less cost. Use of risk transfer as a mitigation strategy with no consideration but cost may lead to; unsuccessful mitigation of risk consequences, failure project risk management plan, and consequently project failure. Contingency fund is used to mitigate the occurred risk items over project life cycle. Its allocation also represents additional challenges for parties involved. Contingency has different meaning for each party, for example owners and contractors consider the contingency fund as a source for additional cost and profit respectively. Ineffective allocation of contingency fund may lead to undesirable results on project cost and schedule. Reliable contingency estimating methodology helps users to allocate appropriate amount of contingency for each risk item. Likewise, Successful mitigation strategies increases user control over depletion and re-allocation of contingency over project life cycle. This paper differentiates between two types of contingency; pre-mitigation, and post mitigation. It also proposes a new method to estimate both contingencies using fuzzy set theory and a newly introduced set of quantitative coefficients for probability of occurrence and consequence of each risk item.

\section{Background}

Fuzzy set theory has been introduced in 1965 by Zadeh to represent uncertainty associated with an element using a membership function [1]. Dealing with risk components (i.e. probability of occurrence and consequence) imposes the deal with uncertainties associated with their input. Therefore, fuzzy set theory has been implemented to incorporate vagueness and uncertainty associated with input of each risk component. Considering that, the review focuses on methodologies which employ fuzzy set theory in contingency estimating.

Estimating right amount of contingency and its associated uncertainty motivates practitioners and researchers to develop several estimating methodologies using fuzzy set theory. These methods can be categorized into three types; 1) qualitative [2,3], 2) quantitative [4, 5], and 3) hybrid [6, 7]. Qualitative methods helps user to prioritize risk items based on qualitative 
information and allocate contingency to mitigate high level risk items. Quantitative methods calculate risk value (RV) [4], as multiplication of probability of occurrence $(\mathrm{P})$ and consequence $(\mathrm{C})$, of each risk item being considered. Hybrid methods evaluate qualitative risk value used to calculate the quantitative value, and contingency [6]. Estimating pre-mitigation contingency implicitly assumes that each risk item occurs with a certain probability and provokes some consequences [4-6]. However, estimating contingency of a risk item regardless the mitigation strategies, used to alleviate its consequences, could generate an excess of contingency fund. Thus, this excess may represent an additional source of high level risk (i.e. profit for contractors) and generate, in case of misuse, undesirable results on construction projects [8]. Considerably less work has been directed towards evaluation and allocating of mitigation strategies for each risk item. Risk mitigation has been treated using three approach; 1) proposing a list of actions [9] which can be used to mitigate a particular type of risk [10] (i.e. financial) in a specific industry [11] (i.e. construction, oil and gas, and Renewable Energy), 2) Collecting data about successful mitigation strategies from practitioners and professional using a questionnaire [12, 13], and 3) comparing several mitigation strategies [14], including "no action" strategy, selected for mitigation a set of risk items. Lack of evaluation and selection of effective risk mitigation strategies lead to absence of estimating post mitigation methodologies.

\section{Proposed methodology}

The proposed method aims to address a number of the shortcomings of existing methods for contingency estimating and the absence of reliable mitigation strategy evaluation methods. The method allows for the differentiation between two types of contingency estimating methods; 1) pre-mitigation which calculates and allocates the contingency to each risk item that is needless to be mitigated, 2) post mitigation which calculates and allocates contingency to each risk item that needs to be mitigated (i.e. high level risk). The proposed method includes four steps:

1. Calculation of Pre-mitigation contingency for each risk items associated with the project regardless of the need for mitigation strategy.

2. Evaluation of mitigation strategy in respect to efficiency and cost.

3. Calculation of Post mitigation strategy for each mitigated risk using one mitigation strategy or more.

Needless to say that pre-mitigation strategy of risk items with no mitigation strategy equals to their post mitigation contingency. Thus, total project contingency can be calculated as the arithmetic sum of post mitigation contingencies allocated to risk items associated with the project.

\subsection{Pre-mitigation contingency estimating}

This paper incorporates a generalized version of the contingency estimating method developed by the authors [6]. This method uses quantitative and 
qualitative assessment of risk items associated with the project using fuzzy set theory. First, experts evaluate, using a pre-defined scale (i.e. from 1 to 5), probability and consequence of each risk item using fuzzy number (Linguistic or Numeric). Using the method described in [6] to convert linguistic fuzzy number into numeric, the fuzzy risk components (i.e. probability of occurrence and consequence) can be calculated as arithmetic average of experts evaluations as follows:

$$
\begin{aligned}
& \widetilde{\mathrm{C}}_{\mathrm{i}}=\left[\frac{1}{\mathrm{~m}} \sum_{\mathrm{j}=1}^{\mathrm{m}} \mathrm{c}_{\mathrm{ij} 1}, \frac{1}{\mathrm{~m}} \sum_{\mathrm{j}=1}^{\mathrm{m}} \mathrm{c}_{\mathrm{ij} 2}, \frac{1}{\mathrm{~m}} \sum_{\mathrm{j}=1}^{\mathrm{m}} \mathrm{c}_{\mathrm{ij} 3}, \frac{1}{\mathrm{~m}} \sum_{\mathrm{j}=1}^{\mathrm{m}} \mathrm{c}_{\mathrm{ij} 4}\right] \\
& \widetilde{\mathrm{P}}_{\mathrm{i}}=\left[\frac{1}{\mathrm{~m}} \sum_{\mathrm{j}=1}^{\mathrm{m}} \mathrm{p}_{\mathrm{ij} 1}, \frac{1}{\mathrm{~m}} \sum_{\mathrm{j}=1}^{\mathrm{m}} \mathrm{p}_{\mathrm{ij} 2}, \frac{1}{\mathrm{~m}} \sum_{\mathrm{j}=1}^{\mathrm{m}} \mathrm{p}_{\mathrm{ij} 3}, \frac{1}{\mathrm{~m}} \sum_{\mathrm{j}=1}^{\mathrm{m}} \mathrm{p}_{\mathrm{ij} 4}\right]
\end{aligned}
$$

The risk value can be calculated using the fuzzy multiplication operation as follows:

$$
\widetilde{R_{l}}=\left[C_{i 1} \times P_{i 1}, C_{i 2} \times P_{i 2}, C_{i 3} \times P_{i 3}, C_{i 4} \times P_{i 4}\right]
$$

The center of area (COA) defuzzification method described in [15] can be used to defuzzify the risk value $\left(\mathrm{R}_{\mathrm{i}}\right)$ of equation 3 . Similar to risk contingency (RC) estimation outlined in [6], pre-mitigation contingency (PREMC) for each risk item (i) can be expressed as follows:

$$
\operatorname{PREMC}_{\mathrm{i}}=\frac{\mathrm{R}_{\mathrm{i}} \times \mathrm{EMV}\left(\mathrm{C}_{\mathrm{i}}\right)}{\text { Scale }\left(\mathrm{P}_{\mathrm{i}}\right) \times \text { Scale }\left(\mathrm{C}_{\mathrm{i}}\right)}
$$

where, $R_{i}$ represents the pre-mitigation risk value of a risk (i) calculated using fuzzy set theory.

EMV $\left(\mathrm{C}_{\mathrm{i}}\right)$ represents the expected monetary values of the consequences associated with the risk item being considered.

Scale $\left(\mathrm{P}_{\mathrm{i}}\right)$, and scale $\left(\mathrm{C}_{\mathrm{i}}\right)$ represent the higher values of scales used for probability of occurrence and consequence assessment, respectively (i.e. consequence scale from 1 to $7-$ scale $(C)=7$ ).

\subsection{Evaluation of mitigation strategy}

Each risk has a mitigation strategy which consists of one or more actions. Mitigation strategy can be evaluated based on its efficiency on decreasing probability of occurrence, and on alleviating consequences of its respective risk. Thus, two factors have been introduced; MEFP and MEFC which represent mitigation efficiency factors on probability and consequence respectively. Mitigation efficiency factor (MEF) has been also introduced to combine the mitigation strategy effects on probability (MEFP) and consequence (MEFC) of each risk item (i) being considered. 
Each expert (j) evaluates a mitigation strategy contribution factor (i.e. percentage) for each risk (i) components. Arithmetic average method is used to calculate MEFPi, and $\mathrm{MEFC}_{\mathrm{i}}$ as follows:

$$
\begin{aligned}
\operatorname{MEFP}_{i} & =\frac{1}{n} \times \sum_{j=1}^{n} \operatorname{MEFP}_{i j} \\
\operatorname{MEFC}_{i} & =\frac{1}{n} \times \sum_{j=1}^{n} \operatorname{MEFC}_{i j}
\end{aligned}
$$

where, MEFP $\mathrm{i}_{\mathrm{ij}}$, and $\mathrm{MEFP}_{\mathrm{ij}}$ represent mitigation strategy contribution factors on probability and consequence of risk (i) evaluated by expert (j).

$\mathrm{n}$, represents the number of experts participating in the process.

MEFi combines the two factors $\left(\mathrm{MEFP}_{\mathrm{i}}\right.$, and $\left.\mathrm{MEFP}_{\mathrm{i}}\right)$ in order to calculate the overall contribution factor of the mitigation strategy being evaluated on risk (i). PEFi can be calculated as follows:

$$
\mathrm{MEF}_{\mathrm{i}}=\mathrm{MEFP}_{\mathrm{i}}+\mathrm{MEFC}_{\mathrm{i}}-\mathrm{MEFP}_{\mathrm{i}} \times \mathrm{MEFC}_{\mathrm{i}}
$$

\subsection{Post-mitigation contingency estimating}

This paper introduces also planned efficiency which makes use of mitigation efficiency factor (MEF) calculated in the previous step, and the ratio of mitigation strategy cost over pre-mitigation contingency. PEF can be represented as follows:

$$
\mathrm{PEF}_{\mathrm{i}}=\mathrm{MEF}_{\mathrm{i}}-\frac{\mathrm{MSC}}{\mathrm{PREMC}_{i}}
$$

Thus, post mitigation contingency can be estimated as follows:

$$
\text { POSTMC }_{\mathrm{i}}=\left(1-\mathrm{PEF}_{\mathrm{i}}\right) \times \mathrm{PREMC}_{\mathrm{i}}
$$

Post mitigation contingency of each risk item is estimated based on its mitigation strategy. Needless to say, Post mitigation contingency of a risk without mitigation strategy equals to its pre-mitigation contingency. The post mitigation contingency of all risk items can be added together to estimate total project contingency (TPC) as follows:

$$
\mathrm{TPC}=\sum_{\mathrm{i}=1}^{\mathrm{n}} \mathrm{POSTMC}_{\mathrm{i}}
$$

where, $\mathrm{n}$ is the number of risks, with or without mitigation strategy, associated with the project. 
Estimating post mitigation contingency helps user to estimate project contingency, with reliable level of confidence. It also allows user to allocate contingency for each risk item independently which can avoid misuse and unnecessary re-allocation of unused contingency. Estimating post mitigation contingency may avert, to a certain limit, the project from cost overrun and schedule delay. It helps users to avoid unnecessary reservation of fund which can be used for another project.

\section{Case example}

The example presented here is designed to illustrate the capacity and capabilities of proposed method in estimating post mitigation project contingency. Let assume that tight project schedule (TPS) represents a risk item associated with that project. Risk components have been evaluated by five experts using numeric fuzzy number with a scale from 1 to 5 as shown in Table 1. Expected Monetary Value (EMV) of the total consequences, which may arise from the occurrence of tight project schedule risk, is considered to be $\$ 70,000$. Additional work shift is considered as a mitigation strategy, and its efficiency factors on probability and consequence are evaluated by the experts as shown in Table 1. Assuming cost of that additional shift equals to $\$ 5 \mathrm{~K}$ which includes costs associated with additional requirements for site operations (i.e. lighting). This cost also excludes costs of materials and man-hours allocated for each activity which are assumed to be the same.

Table 1: Input data for TPS risk.

\begin{tabular}{|c|c|c|c|c|c|c|}
\hline Experts & Risk (i) & $\overline{C_{i}}$ & $\mathrm{P}_{\mathrm{i}}$ & MS & $\mathrm{MEFC}_{\mathrm{ij}}$ & $\mathrm{MEFP}_{\mathrm{ij}}$ \\
\hline E1 & \multirow{5}{*}{ TPS } & {$[4,5,5,5]$} & {$[1,3,3,5]$} & \multirow{5}{*}{$\begin{array}{l}\text { Additional } \\
\text { Shift }\end{array}$} & 0.6 & 0.7 \\
\hline E2 & & {$[2,3,3,4]$} & {$[1,2,2,3]$} & & 0.7 & 0.8 \\
\hline E3 & & {$[3,4,4,5]$} & {$[3,3,4,4]$} & & 0.45 & 0.6 \\
\hline E4 & & {$[2,3,3,5]$} & {$[2,3,3,4]$} & & 0.35 & 0.4 \\
\hline E5 & & {$[2,2,3,3]$} & {$[3,3,4,5]$} & & 0.8 & 0.9 \\
\hline
\end{tabular}

Table 2: Calculation of pre-mitigation contingency (PREMC).

\begin{tabular}{|c|c|c|c|c|c|}
\hline $\begin{array}{c}\text { Risk } \\
(\mathrm{i})\end{array}$ & $\mathrm{C}_{\mathrm{i}}$ & $\mathrm{P}_{\mathrm{i}}$ & $\mathrm{R}_{\mathrm{i}}$ & $\mathrm{R}_{\mathrm{i}}$ & PREMC \\
\hline TPS & {$[2.6,3.4,3.6,4.4]$} & {$[2,2.8,3.2,4.2]$} & {$[5.2,9.5,11.5,18.5]$} & 11.18 & $\$ 31.3 \mathrm{~K}$ \\
\hline
\end{tabular}


Table 3: Calculation of post-mitigation contingency (POSTMC).

\begin{tabular}{|c|c|c|c|c|c|c|}
\hline Mitigation Strategy & MEFC $_{i}$ & MEFP $_{i}$ & MEF $_{i}$ & MSC & PEF $_{i}$ & POSTMC \\
\hline Additional Shift & 0.58 & 0.68 & 0.866 & $\$ 5 \mathrm{k}$ & 0.71 & $\$ 9.1 \mathrm{~K}$ \\
\hline
\end{tabular}

The procedure presented in Tables 1,2 and 3 can be used to estimate post mitigation contingency for all risk items associated with construction project. The post mitigation contingency shown in Table 3 represents only $29 \%$ of pre-mitigation contingency represented in Table 2. The difference between PREMC and POSTMC indicates less required amount of project contingency. Thus, contingency savings, in a large-scale project, can be significant. Calculation of contingency based on mitigation strategy used to mitigate risk items being considered is expected to assist users in identifying unused contingency funds (i.e. called also reserve contingency).

\section{Conclusions and recommendations}

Contingency estimating and its utilization represent considerable challenges for team members of construction projects. This paper introduces a reliable contingency estimating method using fuzzy theory and a set of qualitative and quantitative factors for its application. The proposed method differentiates between two types of contingency pre-mitigation and post mitigation. It also estimates post mitigation contingency taking into account the cost of each mitigation strategy being considered and its efficiency. The case example illustrates the capabilities of proposed method in estimating contingency. It also shows its useful application in cost saving by estimating and allocating contingency at the risk item level; which can increase project managers' control over its depletion and re-allocation. The example demonstrates applicability of proposed method; however its efficiency and accuracy can be further investigated using a case study of real construction projects.

\section{References}

[1] Zadeh, L. "Fuzzy Sets", Information and Control, Vol. 8, pp. 338-353, 1965.

[2] Tmošaitienè, J., Zavadskas, K. and Turskis, Z., "Multi-criteria risk assessment of a construction project", Information Technology and Quantitative n Management, vol. 17, no. 2013, pp. 129-133, 2013.

[3] Nieto-Morote, A. and Ruz-Vila, F., "A fuzzy approach to construction project risk assessment", International Journal of Project Management, vol. 29, no. 2011, pp. 220-231, 2011.

[4] Moselhi, O. and Salah, A., "Fuzzy Sets-Based Contingency Estimation and Management", in ISARC 29th Proceedings, Eindhoven, The Netherlands, 2012. 
[5] Shaheen, A., Robinson, A. F. and Aburizk, S. M., "Fuzzy Numbers in Cost Range Estimating", Construction Engineering and Management, vol. 133, no. 4, pp. 325-334, 2007.

[6] Salah, A. and Moselhi, O., "Quantitative and qualitative risk in EPCM projects using fuzzy set theory", in IFSA World Congress and NAFIPS Annual Meeting (IFSA/NAFIPS), Edmonton, AB, 2013.

[7] Marhavilas, P., Koulouriotis, D., and Gemeni, V., "Risk Analysis and Assessment Methodologies in the Work Sites: On a Review, Classification,and Comparative Study of the Sientific Literature of the Period 2000-2009", Journal of Loss Prevention in the Process Industries, vol. 24, no. 5, pp. 477-523, 2011 a.

[8] Risner, R., "Auditing Construction Contingency," Association of healthcare internal auditors, pp. 37-38, March 2010.

[9] Agrawal, A., "Risk Mitigation Strategies for Renewable Energy Project Financing", Strategic Planning for Energy and the Environment, vol. 32, no. 2, pp. 9-20, 2012.

[10] Hallowell, M. R., and Gambatese, J. A., "Construction Safety Risk Mitigation", Journal of Construction Engineering And Management, vol. 135, no. 2009, pp. 1316-1323, 2009.

[11] Baker, S., Ponniah, D., and Smith, S., "Risk response techniques employed currently for major projects," Construction Management and Economics, vol. 17, no. 2, pp. 205-213, 1999.

[12] Abdul-Rahman, H., Loo, S. C. and Wang, C., "Risk identification and mitigation for architectural, engineering, and construction firms operating in the Gulf region", Canadian Journal of Civil Engineering, vol. 39, no. 1, pp. 55-71, 2012.

[13] Chan, J. H. L., Chan, D. W. M., Chan, A. P. C. and Lam, P. T. I., "Risk mitigation strategies for guaranteed maximum price and target cost contracts in construction: A factor analysis approach", Journal of Facilities Management, vol. 10, no. 1, pp. 6-25, 2012.

[14] Fang, C. and Marle, F., "A simulation-based risk model for decision support for project risk management", Decision Support Systems, pp. 635-644, 2012.

[15] Nieto-Morote, A. and Ruz-Vila, F., "A fuzzy approach to construction project risk assessment", International Journal of Project Management, Vol. 29,, pp. 220-231, 2011. 